ACADEMIA ROMÂNĂ

Revue Roumaine de Chimie

http://web.icf.ro/rrch/
Rev. Roum. Chim.

2020, 65(7-8), 707-709

DOI: $10.33224 /$ rrch.2020.65.7-8.08

\title{
CONCERNING THE LOGARITHMIC LAW USED IN ADSORPTION-DESORPTION OF SOLID-GAS REACTIONS
}

\author{
Niculae I. IONESCU* and Veronica BRĂTAN \\ "Ilie Murgulescu" Institute of Physical Chemistry of the Roumanian Academy, 202 Spl. Independentei, \\ 060021 - Bucharest, Roumania
}

$$
\frac{1}{\mathrm{q}}=\frac{\mathrm{N}}{\mathrm{b}} \ln \mathrm{t}
$$

\section{INTRODUCTION}

The formal kinetics of gas adsorption phenomena of gases on solid surfaces is mostly described by the logarithmic rate law. In case of adsorption the integral form of this equation is:

$$
\mathrm{q}=\frac{1}{\mathrm{~b}} \cdot\left[\ln \left(\mathrm{t}+\mathrm{t}_{0}\right)-\ln \mathrm{t}_{0}\right]
$$

and in the differential form:

$$
\frac{\mathrm{dq}}{\mathrm{dt}}=\mathrm{a} \cdot \exp (-\mathrm{bq})
$$

where $\mathrm{q}$ is the adsorbed gas quantity at the $\mathrm{t}$ moment, $\mathrm{a}$ and $\mathrm{b}$ are constants and $\mathrm{t}_{0}=\frac{1}{\mathrm{ab}}$ if $\mathrm{t}=0$, $\mathrm{q}=0$.

But the differential form (2) can be also represented by an other equation, namely:

$$
\frac{\mathrm{dq}}{\mathrm{dt}}=\frac{1}{\mathrm{~b}} \cdot \frac{1}{\mathrm{t}+\mathrm{t}_{0}}
$$

These form of equation (1)-(3) have been intensively studied ${ }^{1-7}$ and many models have been proposed, based on sites number variations, variable activation energy on nonuniform surfaces. Other equations concerning the adsorptiondesorption phenomena in solid-gas reactions can be found resumed in a table presented by Maria and Luta. ${ }^{8}$

In the present paper we analyze a model which leads to a (3) type equation.

\section{THE MODEL}

The adsorption processes of gases on solid surface, can be assimilated by a probabilistic discontinuum process, $\mathrm{q}$, which progresses in discrete steps in a background of fluctuations.

The model is:

$$
\frac{\mathrm{dq}}{\mathrm{dt}}=\mathrm{Npq}^{2} \text { and } \frac{\mathrm{dp}}{\mathrm{dt}}=\mathrm{bp}^{2}
$$

where $\mathrm{N}$ is the number of events per unit time which are capable of carrying the process forward,

\footnotetext{
*Corresponding author: ionescu@icf.ro
} 
but have only a probability, $\mathrm{p}$, of doing it and $\mathrm{b}$ is a constant. The physical signification of $\mathrm{q}, \mathrm{N}$ and $\mathrm{p}$ from equations (4) are $\mathrm{q}-\mathrm{a}$ monolayer of the adsorbed gas on a surface, $\mathrm{N}$ - the number of impact of gas molecules with the surface expressed per unit area and unit time and $p$ - the number of free sites, respectively. The evolution of the process is measured by the first equation of the system (4).

The model presented in equations (4) is a modification of an old model of Landsberg. ${ }^{9,10}$ The differences between the old model and this one consist i) in the introduction of the term $\mathrm{q}^{2}$ in the first equation (4) and ii) the modified sign ("+" instead of "-") in the second equation of the system..

From the second equation of the system (4) one obtains:

$$
\mathrm{p}^{-2} \mathrm{dp}=\mathrm{bdt}
$$

and by integration:

$$
\mathrm{p}=-\frac{1}{\mathrm{bt}}
$$

With this value of $p$ given by equation (6), the first equation of the system (4) becomes:

$$
\frac{\mathrm{dq}}{\mathrm{dt}}=-\frac{\mathrm{N}}{\mathrm{bt}} \mathrm{q}^{2}
$$

or

$$
\mathrm{q}^{-2} \mathrm{dq}=-\frac{\mathrm{a}}{\mathrm{bt}} \mathrm{dt}
$$

By a new integration one obtains finally:

$$
\frac{1}{\mathrm{q}}=\frac{\mathrm{N}}{\mathrm{b}} \ln \mathrm{t}
$$

We assume that the desorption reaction of the adsorbed gas starts when the surface is total covered. The necessary time to cover the surface by the gas in a Langmuir approximation is $\mathrm{t}_{0}$. That is why equation (9) becomes:

$$
\frac{1}{\mathrm{q}}=\frac{\mathrm{N}}{\mathrm{b}} \ln \left(\mathrm{t}+\mathrm{t}_{0}\right)
$$

The same equation (11) was obtained from the system:

$$
-\frac{\mathrm{dq}}{\mathrm{dt}}=\mathrm{Npq}^{2} \text { and }-\frac{\mathrm{dp}}{\mathrm{dt}}=\mathrm{bp}^{2}
$$

Considering that the number of gas molecules existing on a surface is constant in a Langmuir aproximation then:

$$
\mathrm{q}_{\mathrm{t}}=\mathrm{q}_{\mathrm{a}}+\mathrm{q}_{\mathrm{d}}
$$

where $\mathrm{q}_{\mathrm{t}}$ is a total gas quantity in a monolayer, $\mathrm{q}_{\mathrm{a}}-$ the adsorbed gas on a surface and $\mathrm{q}_{\mathrm{d}}$ - the gas which can be desorbed from the covered surface in conformity with the reaction $\mathrm{A}_{\mathrm{ad}} \leftrightarrow \mathrm{A}_{\text {des }}$ and $\mathrm{q}_{\mathrm{d}}, \mathrm{q}_{\mathrm{a}}$ $<\mathrm{q}_{\mathrm{t}}$.

In the case of $\mathrm{q}_{\mathrm{a}}$ then:

$$
\frac{1}{\mathrm{q}_{\mathrm{t}}-\mathrm{q}_{\mathrm{a}}}=\frac{\mathrm{N}}{\mathrm{b}} \ln \left(\mathrm{t}+\mathrm{t}_{0}\right)
$$

When $t$ increases, $q_{t}$ diminishes, the result being, according to equation (11), an increase of $\mathrm{q}_{\mathrm{d}}$, the desorbed quantity.

In the case of $\mathrm{q}_{\mathrm{d}}$ :

$$
\frac{1}{q_{t}-q_{d}}=\frac{N}{b} \ln \left(t+t_{0}\right)
$$

The increase of time $t$ means an increase of $q_{a}$, the re-adsorbed gas.

And so, equation (9), represent both processes: adsorption and desorption of a gas from the surface, if the gas layer is a Langmuir one.

Till now there doesn't exists a general model for the explanation of the logarithmic law used in sorption phenomena on solid surfaces. The impossibility to propose a model explaining the adsorption or desorption only on the basis of fitting the experimental data with the logarithmic equation can be due to several reasons: (i) the existence of two different equations, each based on an other model leading to the same integral equation of the logarithmic law; ${ }^{11}$ (ii) the generalized Landsberg's model ${ }^{12}$ (iii) the existence of a surface heterogeneity; ${ }^{13,14}$ (iv) the existence of conditions when the logarithmic law represent nothing else than a sum of other logarithmic equations; ${ }^{15}(\mathrm{v})$ the model based on the association of active sites; ${ }^{16}$ (vi) the existence of an extra energy obtained during the formation of the solid surface ${ }^{17,18}$ (vii) the surface charge transfer phenomena at the solid-gas interface ${ }^{19-27}$

It must be noted that the simple logarithmic law is not sufficiently flexible, the deviations in the initial stage of adsorption or desorption, discontinuities in the $\mathrm{q} / \mathrm{lnt}$ plots or rates of readsorption on surfaces containing adsorbed gas cannot be explained without farther assumptions. In order to claim the existence of a logarithmic kinetics for adsorption or desorption processes of gases from solid surfaces it is necessary to fit the experimental data over a long range of experimental parameters. $^{23-25}$ 
The simple models described till now present only normal behaviors of adsorption or desorption reactions in solid-gas systems.

\section{CONCLUSIONS}

The logarithmic rate law observed in adsorption or desorption of a monolayer of gases on/from solid surfaces can be explained with the same equation in a Langmuir approximation.

\section{REFERENCES}

1. C. Aharoni and F. C. Tompkins, Adv. Catalysis, 1970, $20,1$.

2. K. Hauffe and S. R. Morrison, "Adsorption" de Gruyter Verlag, Berlin, 1974, p. 87

3. P. Fejes, "Contact Catalysis", Z.G. Szabo and D. Kallo (Eds.), Akademiai Kiado, vol.1, Budapest, 1976, p. 225.

4. S. R. Morrison, "The Chemical Physics of Surfaces", Plenum Press, New York and London, 1978, p. 46, 241.

5. E. I. Segal, C. Iditoiu, N. Doca and D. Fatu, "Cataliza si catalizatori”, Ed. Facla, Timisoara, 1986, p. 40.

6. E. I. Segal, N. I. Ionescu, D. M. Razus and I. N. Salageanu, "Cinetica reactiilor catalitice eterogene", vol. I, Ed. Academiei Române, 1992, p. 87.
7. E. Angelescu and A. Szabo, "Cataliza Eterogena", Ed. Briliant, Bucuresti, 1998, p.103.

8. G. Maria and I. Luta, Chem. Papers, 2011, 65, 542.

9. P. T. Landsberg, J. Chim. Phys., 1955, 23, 1079.

10. P. T. Landsberg, J. Appl. Phys., 1962, 33, 2251.

11. N. I. Ionescu and B. Aurian Blajeni, Rev. Roum. Chim., 1973, 18, 203.

12. N. I. Ionescu and B. Aurian Blajeni, Rev. Roum. Chim., 1977, 22, 353.

13. C. F. Cerofolini, Z. Phys. Chem. (Leipzig), 1978, 259, 1020.

14. N. I. Ionescu, Rev. Roum. Chim., 1980, 25, 663.

15. N. I. Ionescu, Rev. Roum. Chim., 1979, 24, 399.

16. N. I. Ionescu, Bulg. Chem. Commun., 1992, 25, 39.

17. N. I. Ionescu, Surf. Sci., 1976, 61, 294.

18. N. I. Ionescu, Rev. Roum. Chim., 1979, 24, 83.

19. N. I. Ionescu, Z. Phys. Chemie- Neue Folge, 1978, 109, 95.

20. N. I. Ionescu, Rev. Roum. Chim., 1992, 37, 509.

21. N. I. Ionescu, Rev. Roum. Chim., 1995, 40, 629.

22. N. I.Ionescu and M. Caldararu, Rev. Roum. Chim., 2002, 47, 1213.

23. N. I.Ionescu and M. Caldararu, Rev. Roum. Chim., 2006, 51, 521.

24. N. I. Ionescu, Rev. Roum. Chim., 2008, 53, 535.

25. N. I.Ionescu and M. Caldararu, Rev. Roum. Chim., 2008, 53, 608.

26. N. I.Ionescu, Rev. Roum. Chim., 2011, 56, 483.

27. V. Bratan and N. I. Ionescu, Rev. Roum. Chim., 2019, 64, 981. 
